\title{
Erratum: Technologien statt Branchen: Eine Neuauswertung der FuE-Erhebung 2015
}

\section{Andreas Kladroba $\cdot$ Muhamed Kudic $\cdot$ Katharina Friz Tobias Buchmann • Patrick Wolf}

Online publiziert: 27. August 2018

(C) Springer-Verlag GmbH Germany, part of Springer Nature 2018

\section{Erratum:}

AStA Wirtsch Sozialstat Arch 2018

https://doi.org/10.1007/s11943-018-0226-z

In der Originalveröffentlichung wurde der Name der Autorin Katharina Friz versehentlich falsch geschrieben.

Wir bitten, dieses Versehen zu entschuldigen.

Der Originalbeitrag wurde nachträglich korrigiert.

Die Online-Version des Originalartikels ist unter https://doi.org/10.1007/s11943-018-0226-z zu finden.

\footnotetext{
A. Kladroba $(\bowtie)$

FOM Hochschule für Oekonomie und Management, Leimkugelstr. 6, 45141 Essen, Deutschland

E-Mail: andreas.kladroba@fom.de

M. Kudic $\cdot$ K. Friz

Universität Bremen, Hochschulring 4, 28359 Bremen, Deutschland

T. Buchmann · P. Wolf

Zentrum für Sonnenenergie- und Wasserstoff-Forschung, Meitnerstr. 1, 70563 Stuttgart, Deutschland
} 